\title{
Los periódicos gratuitos con contenidos especializados en la Comunidad Autónoma Vasca
}

\author{
Dra. María Teresa Santos Díez \\ Profesora Titular. Fac. CC.SS. y de la Comunicación. UPV/EHU
}

\section{RESUMEN}

En la Comunidad Autónoma Vasca han surgido en la última década medios de comunicación con escasos recursos económicos que intentan atraer una publicidad principalmente local. Son los denominados periódicos gratuitos. Este artículo analiza las características de estos periódicos gratuitos con contenidos especializados, tales como Montañas y Tiempo Libre (1994) o Bizkai-Lan (1997). Se estudian especialmente sus contenidos, tirada, cobertura geográfica, formato y distribución.

\section{ABSTRACT}

In the Basque autonomous region, media with limited economic resources, that try to attract a local publicity, have appeared at the last decade. They are called free newpapers. This article analyses the characteristics of these free newpapers with specialized centents, such as Montañas y Tiempo Libre (1994) or Bizkai-Lan (1997). Special emphasis is given both to the study of its contents, printing, geographic coverage, format and distribution.

Palabras claves: Periódicos gratuitos/Contenidos especializados/Comunidad Autónoma Vasca/ Publicidad local.

Key Words: Free newpapers/Specialized contents/Basque Autonomous region/Local Publicity.

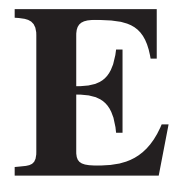
n la Comunidad Autónoma Vasca junto a las grandes empresas informativas, van a surgir y desarrollarse otros medios con escasos recursos económicos que intentan atraer una publicidad principalmente local. Nos referimos a los periódicos gratuitos que empiezan a surgir como una forma positiva dentro de un mercado cada vez más competitivo. Existen diversas tipologías, aunque en el estudio solo se han tenido en cuenta los gratuitos especializados, que son aquellas publicaciones promovidas por editores que asumen los riesgos y que distribuye de manera gratuita unos contenidos que se centran en un tema único que abordan en profundidad como por ejemplo la montaña, el deporte, la industria, construcción, servicios y agricultura entre otros muchos.

Las publicaciones gratuitas se envían a un destinatario que recibe unos contenidos sin mediar por ello ninguna prestación económica. No obstante, solo es 
posible efectuar el regalo si el editor tiene cubiertos con publicidad los gastos que le origina su publicación. La proximidad entre el lector, editor y anunciante es un hecho que contemplan los editores y tanto en los contenidos como en la venta de los espacios a los anunciantes. El regalar la publicación introduce un elemento diferenciador en el mercado que puede provocar modificaciones en el mercado de la prensa de pago. Este estudio se va a centrar únicamente en aquellos periódicos que se financian mediante la publicidad y que abordan un tema único tratándolo en profundidad como puede ser la montaña, el deporte, la industria, construcción, tiempo de ocio entre otros muchos.

\section{Características}

Son innumerables las publicaciones que se editan desde diversos estamentos sociales y culturales con contenidos especializados, aunque la publicidad debe ser suficiente para sostenerlo y en cierto modo los contenidos están supeditados a la propia publicidad. Esto requiere necesariamente una especialización del lector. Pero también hay que tener en cuenta, que algunos temas que con anterioridad sólo se abordaban desde revistas muy especializadas hoy día forman parte de los suplementos. En el caso de los gratuitos es la propia empresa editora quien elige a los receptores a los cuales quiere llegar. Aunque, no es del todo exacto que el receptor no paga nada por la publicación ${ }^{1}$.

Es cierto que no paga dinero, pero el paga habitualmente con su atenciónsu tiempo, por tanto -, y esto es lo que realmente busca el editor. Sólo si el editor presenta garantías razonables de que un porcentaje significativo de quien reciban la publicación le dedicaran al menos unos minutos lograra convencer al anunciante de que inserte publicidad en la misma.

Los contenidos están relacionados con la publicidad y los anunciantes saben perfectamente que sus lectores son más homogéneos. Las revistas especializadas de pago utilizan un lenguaje especifico y concreto con la inclusión de términos con cierta complejidad. Es evidente que en su conjunto las publicaciones gratuitas tienen coincidencias claras entre las que destacan:

1) Inician una experiencia comunicativa dentro de un conglomerado de medios impresos plenamente consolidados.

2) Captan una publicidad especifica de ámbito local que en muchos casos no accede a los medios de pago.

3) Son publicaciones que intentan encontrar un lugar dentro de la pluralidad de medios que existen y por lo tanto buscan contenidos que ellos abordan con la

1 COCA, Cesar y PEÑALVA, José Luis. Modelos de los medios de comunicación social. U.P.V. Bilbao, 1998, p.163. 
suficiente profundidad o simplemente no incluyen por el amplio caudal informativo del que disponen cada día y que necesariamente les obliga a realizar una selección.

4) Su ámbito de cobertura es local.

5) Los contenidos tienen un marcado carácter divulgativo, cultural y de entretenimiento, pero relacionado con su ámbito de cobertura.

\section{1) El origen de las publicaciones}

En la Comunidad Autónoma Vasca en el año 1994 surgieron el 14,28 \% de los gratuitos especializados. Sin embargo, no se producen más experiencias de este tipo hasta el año 1997 con el 42,86 \% de ellos, situación que se repite en el año 2000.

En diciembre de 1994 comienza a editarse Montañas y Tiempo Libre promovido por la Editorial Ocio y Aventura. Sus contenidos especializados van destinados a un público aficionado a los viajes, el deporte, la aventura y el ocio. Distribuye con una periodicidad trimestral 40.000 ejemplares en aquellos lugares relacionados con las actividades que promueve como son las tiendas de deportes y agencias de viajes del País Vasco, Navarra y Aragón, por lo tanto su reparto es más selectivo que en otras publicaciones de este tipo.

Bizkai-Lan inicia su andadura el 15 de julio de 1997 con una periodicidad trimestral y una tirada de 60.000 ejemplares que se reparten en la Margen Izquierda y zona de Encartaciones principalmente mediante buzoneo, aunque también se puede conseguir por suscripción ${ }^{2}$. Posteriormente, pasa a editarse cada dos meses. En un principio era un suplemento destinado a empresas que se incluía con Salgai ${ }^{3}$, pero llego un momento que eran demasiadas páginas y la empresa opta por editar un gratuito con unos contenidos especializados que inciden en unos sectores muy concretos como son industria, construcción, servicios y agricultura, pero con un soporte propio.

En septiembre de 1997 aparece en el mercado La Grada con dos ediciones que cubren ambas márgenes del Nervión:

1) Margen Izquierda con una tirada de 15.000 ejemplares

2 Bizkai-Lan es posible recibirlo en casa junto a las demás publicaciones que edita el grupo por 3.328 pesetas.

3 Salgai esgratuito es un grupo empresarial que entre otras actividades edita los siguientes gratuitos: Salgai Bizkaia comenzó a editarse en el año 1990 con información destinada a la provincia de Vizcaya en general y una tirada de 90.000 ejemplares. Salgai Ezkerraldea empieza a salir en septiembre de 1995 para la Margen Izquierda y Zona Minera con una tirada de 82.000 ejemplares. Salgai Enkarterri surge en noviembre de 1995 con una periodicidad mensual. Presta una mayor atención a la fotografía, las noticias de carácter social y el euskera. Bizkaia Tradición y Fiestas ofrece una amplia información de las fiestas de verano de cada localidad, así como calendario, programa de actos e incluso horario de trenes y autobuses, además de una reseña con los lugares de interés más próximos así como la historia del lugar. 
2) Getxo con 8.000 ejemplares en la zona de Uribe Costa.

Su distribución no se realiza mediante buzoneo como sucede con otros gratuitos, sino que se recoge en el quiosco de manera gratuita junto con los periódicos de pago, en algunos comercios y por correo ${ }^{4}$ El objetivo de la publicación es ofrecer un producto que no existe en el mercado como es la información sobre deporte profesional y de aficionados que se realiza en ambas márgenes. Su estructura interna es jerarquizada y las 20 personas que colaboran se integran en los departamentos comerciales y de redacción. A últimos del año 2000 deja de publicarse la edición de Getxo.

En marzo de 1999 Racing Press comienza a publicarse con una periodicidad mensual y una cobertura de Vizcaya. Su objetivo principal es la divulgación del deporte del motor y todo el conjunto de actividades relacionadas con este sector. La publicación está promovida por ocho personas que se organizan en los departamentos de: dirección; comercial; redacción y distribución. Es una publicación especializada en el deporte del motor con una tirada de 15.000 ejemplares que no se distribuyen como otros gratuitos por buzoneo, sino que se reparten en los establecimientos relacionados con el sector como 2.700 talleres de reparación, compra venta, gasolineras y por suscripción cuyo precio es de 1.000 pesetas anuales.

Wellcome Euskadi empieza a salir en junio de 1999 con una tirada de 40.000 ejemplares y una periodicidad de cada dos meses. Su distribución se realiza mediante deposito en puntos fijos en Bilbao: Museo Guggenheim de Bilbao, Bellas Artes, Etnografía; En Donostia junto al Aquarium, el Palacio de Miramar, Monte Igueldo, jardines de Alderdi Eder y Boulevard, además de hoteles, pensiones y puntos de información turística, además de bares y restaurantes de las tres capitales vascas. Es una publicación con unos contenidos centrados en el turismo junto con información de utilidad para el visitante tanto del Estado como extranjero. Por ello incluye planos, guías de hoteles, restaurantes, cines centros de ocio y entretenimiento principalmente en inglés, francés, castellano y euskera. Tiene formato tabloide y utiliza el color en portada, contraportada y páginas centrales, mientras que el resto de sus páginas son en blanco y negro.

4 Para recibirlo en casa es preciso enviar 500 pesetas en sellos. 
Cuadro n. 1

\section{Montañas Bizkai-Lan Grada Racing Wellcome}

$\begin{array}{lrrrrr}\text { Tirada } & 40.000 & 60.000 & 15.000 & 15.000 & 40.000 \\ \text { Páginas } & 16 & 32 & 24 & 24 & 16 \\ \text { Periodicidad } & \text { Semanal } & 2 \text { meses } & \text { Mensual } & 2 & \text { Meses } \\ \text { Origen } & 1994 & 1997 & 1997 & 1999 & 1999 \\ \text { Distribución } & \text { Tiendas } & \text { Buzoneo } & \text { Tiendas } & \text { Tiendas } & \text { Tiendas } \\ \text { Agencias } & \text { Comercio } & \text { Quiosco } & \text { Gasolinera } & \text { Hoteles } & \\ \text { Cobertura } & \text { País Vasco } & \text { Vizcaya } & \text { Margenes } & \text { Vizcaya } & \text { Autonomía }\end{array}$

\section{2) Los Promotores}

Las publicaciones gratuitas especializadas son impulsadas básicamente desde los siguientes ámbitos:

1) Las empresas pequeñas en el año 1990 constituían la práctica totalidad de las publicaciones de este tipo, mientras que en el año 2000 se reduce al $80 \%$.

2) Las Agencias de comunicación editaban en el año 2000 el $20 \%$ de los gratuitos.

\section{Cuadro n. 2}

\section{Gratuitos Especializados según promotores en la C.A.V.}

$\begin{array}{lrrr} & \underline{\mathbf{1 9 9 0}} & \underline{\mathbf{1 9 9 5}} & \underline{\mathbf{2 0 0 0}} \\ \text { Empresas S.L. } & 100,00 & 0,00 & 80,00 \\ \text { Agencias Publicidad } & 0,00 & 0,00 & 0,00 \\ \text { Grupos comunicación } & 0,00 & 0,00 & 20,00 \\ \text { Asociaciones } & 0,00 & 0,00 & 0,00 \\ \text { Otros } & 0,00 & 0,00 & 0,00\end{array}$

\section{3) Lugar geográfico}

Dentro de la geografía vasca estas publicaciones tienen una distribución muy desigual, y mientas en algunas zonas llegan muchos periódicos en otras no se reparte ninguno. Así tenemos:

1) En Vizcaya se concentran el $81,60 \%$ del total de las publicaciones que se aglutinan:

a) En la Margen Derecha en el año 1994 se publica Montañas. A esta oferta hay que añadir en el año 2000 la Grada Margen Derecha, Racing-Press y Wellcome lo que supone el $31,50 \%$ del total de los gratuitos. 
b) En la Margen Izquierda se reparten ejemplares de la Grada Margen Izquierda especializada en deporte local y Racing-Press que se deposita en talleres y gasolineras y Bizkai-Lan. Esta zona concentra el 39,60\%.

c) En Bilbao Area se distribuyen el $33 \%$ del total de ejemplares de Montañas, La Guía Inmobiliaria entre otros, pero desciende en al año 2000 hasta el $10,50 \%$.

2) Álava es una provincia con escasas experiencias de este tipo, y su difusión en el año 2000 alcanza el 9,20\%.

3) En Guipúzcoa estas publicaciones tienen una incidencia mínima con tan sólo el 9,20\%.

\section{Cuadro n. 3}

\section{Gratuitos Especializados según el lugar geográfico.}

$\begin{array}{lrrr} & \underline{\mathbf{1 9 9 0}} & \underline{\underline{\mathbf{1 9 9 5}}} & \underline{\underline{\mathbf{2 0 0 0}}} \\ \text { VIZCAYA } & 100,00 & 0,00 & 81,60 \\ \text { M.Derecha } & 34,00 & 0,00 & 31,50 \\ \text { M. Izquierda } & 33,00 & 0,00 & 39,60 \\ \text { Bilbao Area } & 33,00 & 0,00 & 10,50 \\ \text { Alto Nervión } & 0,00 & 0,00 & 0,00 \\ \text { ALAVA } & 0,00 & 0,00 & 9,20 \\ \text { GUIPUZCOA } & 0,00 & 0,00 & 9,20\end{array}$

\section{4) Distribución de la mancha}

En cuanto a la distribución de la mancha se producen grandes diferencias: mientras que el La Grada los contenidos de carácter informativo solo suponen el $19,27 \%$, y en Bizkai-Lan alcanzan casi el $61 \%$. La fotografía tiene una mayor presencia en Montañas (36,87\%), y la publicidad oscila entre el 43,08 \% en la Grada y el $15,46 \%$ en Wellcome.

\section{Cuadro n.4}

\section{Distribución de la mancha. Año 2000}

\section{Montañas Bizkai-Lan Grada Racing Wellcome}

$\begin{array}{lrrrrr}\text { Texto } & 38,46 & 60,98 & 19,27 & 46,56 & 58,74 \\ \text { Fotografía } & 36,87 & 15,69 & 33,50 & 15,12 & 23,37 \\ \text { Publicidad } & 20,96 & 21,94 & 43,08 & 36,32 & 15,46 \\ \text { P. Propia } & 3,71 & 1,39 & 4,15 & 2,00 & 2,43\end{array}$


Los editores de los gratuitos con contenido especializado optan por presentar sus publicaciones en formato tabloide.

\section{Cuadro n. 5}

Formato de Gratuitos Especializados en la C.A.V.

$\begin{array}{lrrr} & \underline{\mathbf{1 9 9 0}} & \underline{\mathbf{1 9 9 5}} & \underline{\mathbf{2 0 0 0}} \\ \text { Tabloide } & 100,00 & 100,00 & 100,00 \\ \text { Revista } & 0,00 & 0,00 & 0,00 \\ \text { Otros } & 0,00 & 0,00 & 0,00\end{array}$

\section{5) El reparto de los gratuitos}

Esta prensa eminentemente local encuentra graves problemas para su distribución ante la falta de experiencia en este tipo de publicaciones, tanto por parte de los editores como del público que lo recibe. Por otro lado, la peculiaridad de ser gratuito tiene como consecuencia la ausencia de beneficios para los vendedores tradicionales, que en la mayoría de los casos no aceptan un producto que no les aporta ninguna compensación económica.

Ante esta situación los editores recurren a diversas formas, aunque predomina el depósito en lugares concretos como lo avala el hecho de que en 1995 la totalidad de ellos se distribuían de esta manera.

1) El buzoneo es la fórmula que emplean el $12,50 \%$ de ellos. Es evidente que resulta caro, y además puede llegar a hogares que ese tema no interesa y por lo tanto la publicidad es ineficaz.

2) Por correo se calcula que se envían el $12,50 \%$ de los ejemplares, pero el receptor previamente tiene que pagar los gastos que ocasiona.

3) En deposito en lugares concretos es utilizado por la mitad de los editores como sucede con Racing-Press que prefiere que su publicación se recoja en las gasolineras y tiendas relacionadas con el mundo del motor y Bizkai-Lan también elige esta opción para su reparto.

4) Los quioscos es un lugar muy cómodo para conseguir el gratuito junto con el periódico de pago, como lo hace La Grada Margen Izquierda y Getxo. 
Cuadro n. 6

\section{Reparto de los Gratuitos Especializados en la C.A.V,}

$\begin{array}{lrrr} & \underline{\mathbf{1 9 9 0}} & \underline{\mathbf{1 9 9 5}} & \underline{\underline{\mathbf{2 0 0 0}}} \\ \text { Buzoneo } & 0,00 & 0,00 & 12,50 \\ \text { Correo } & 0,00 & 0,00 & 12,50 \\ \text { Centros comerciales } & 100,00 & 0,00 & 50,00 \\ \text { Encartado } & 0,00 & 0,00 & 0,00 \\ \text { Quioscos } & 0,00 & 0,00 & 12,50 \\ \text { Otros } & 0,00 & 0,00 & 12,50\end{array}$

\section{6) La periodicidad}

Los gratuitos especializados se publican en su mayoría con una periodicidad mensual (50 \%); cada dos meses $(32,32 \%)$ y en el caso de Bizkai-Lan opta por salir a la calle cada dos meses y mientras el $16,66 \%$ lo hace cada tres.

\section{Cuadro n. 7}

\section{La periodicidad de los gratuitos Especializados}

$\begin{array}{lrrr} & \underline{\mathbf{1 9 9 0}} & \underline{\mathbf{1 9 9 5}} & \underline{\mathbf{2 0 0 0}} \\ \text { Semanal } & 100,00 & 0,00 & 0,00 \\ \text { Quincenal } & 0,00 & 0,00 & 0,00 \\ \text { Mensual } & 0,00 & 0,00 & 50,02 \\ 2 \text { Meses } & 0,00 & 0,00 & 33,32 \\ 3 \text { Meses } & 0,00 & 0,00 & 16,66\end{array}$

\section{7) Los Contenidos}

Estas publicaciones buscan la especialización el ámbito locales, pero estos además lo abordan desde un único tema tratándolo con más profundidad. Así podemos señalar Montañas que centra sus contenidos en la montaña en sus diversos aspectos; La Grada Margen Izquierda y Getxo se ocupa del deporte local; Bizkai-Lan, incide en el sector de la industria, construcción, servicios y agricultura y Racing-Press que tiene como objetivo principal la divulgación del deporte del motor y todo el conjunto de actividades relacionadas con el. Así podemos señalar: 


\section{Cuadro n. 8}

\section{Los contenidos en los gratuitos Especializados}

$\begin{array}{lrrr} & \underline{\mathbf{1 9 9 0}} & \underline{\mathbf{1 9 9 5}} & \underline{\mathbf{2 0 0 0}} \\ \text { Motor } & 0,00 & 0,00 & 16,66 \\ \text { Deporte } & 0,00 & 0,00 & 33,32 \\ \text { Viajes } & 0,00 & 0,00 & 33,32 \\ \text { Ocio } & 100,00 & 0,00 & 0,00 \\ \text { Industria } & 0,00 & 0,00 & 16,70\end{array}$

1) En Montañas se ofrece una amplia información a todas aquellas personas cuyo tiempo de ocio lo ocupan en desarrollar actividades al aire libre, como pueden ser turismo, deportes, aventuras, etc.. Además facilita al aficionado a estos deportes la mayor información posible sobre el material necesario para practicar el deporte, los lugares más adecuados e incluso consejos para no correr riesgos innecesarios, por lo que adquiere especial relevancia el equipo adecuado y por ello ofrece las últimas novedades que aparecen en el mercado.

En sus páginas tiene gran importancia la fotografía $(36,87 \%)$, mientras que la publicidad ocupa menos de la cuarta parte de la superficie $(20,96 \%)$. Sus contenidos inciden en tres aspectos básicos:

1) Las Noticias relacionadas con las actividades que se realizan en la montaña como por ejemplo parapente y heliesquí. Los Consejos prácticos sobre la forma de conducir en la nieve o el hielo, el uso de las cadenas en el coche, e incluso trucos que nos resultan de utilidad en algún momento del viaje.

2) Monográficos que dedica a una estación concreta, y aporta informaciones de utilidad como teléfonos de urgencia, horario de autobuses, guía comercial, polideportivos y restaurantes que alcanza más de la cuarta parte de los contenidos de Montañas (26,45\%).

3) En Noticias de interés general se ocupa de divulgar deportes nuevos, así como el equipo adecuado para practicarlo sin riesgo $(13,28 \%)$.

4) En turismo rural incorpora guías con información de utilidad y sugerencias sobre donde dormir, comer y divertirse, así como orientaciones sobre rutas especiales de gran interés cultural en zonas próximas a las estaciones de esquí $(7,14 \%)$.

2) En Bizkai-Lan más de la mitad de su superficie la ocupan los contenidos informativos $(54,19 \%$ y $60,98 \%)$, mientras que la publicidad supone la cuarta parte $(26,37 \%$ y $21,94 \%)$. Sus contenidos los agrupa en las siguientes secciones:

1) La Guía con los teléfonos de interés y horarios de trenes y autobuses $(3,40 \%)$. 
2) Actualidad es una sección que no ha variado mucho (15,92 \%). En ella destacan las noticias relacionadas con la economía, inversiones y proyectos que se van a efectuar en las industrias de la zona.

3) En Infraestructuras incluye las obras que se han realizado o están en fase de ejecución en ese momento (14,90\%).

4) La sección de Trabajo recoge los cursos de formación que ofrecen las empresas o la propia administración, así como la creación de empleo que se produce en las empresas $(19,87 \%)$.

5) En Medio Ambiente se acerca al lector la información de la zona como vertederos, legislación sobre Medio Ambiente y contaminación principalmente, aunque también es cierto que ha sufrido un retroceso importante $(9,43 \%)$.

6) El Suplemento lo dedica a ofrecer información especifica de un polígono industrial o una actividad concreta. Consta de unas diez páginas y se editan cuando se producen acontecimientos excepcionales $(37,38 \%)$.

3) En La Grada casi la mitad de su superficie lo ocupa la publicidad, y el resto se reparte entre texto $(13,86 \%$ y $24,68 \%)$ y fotografía $(31,74 \%$ y $35,36 \%)$. Sin embargo, entre ambas ediciones se aprecian algunas diferencias, así en la Margen Izquierda se incluye más publicidad que en la Margen Derecha $(50,28 \%$ y $35,88 \%)$; y en consecuencia disminuye el espacio de contenidos $(13,86 \%$ y $24,68 \%)$ y fotografía. Sus secciones las distribuye del siguiente modo:

1) Guía de servicios con información de utilidad para el lector: horario de trenes, autobuses y teléfonos $(4,16 \%)$.

2) La página de opinión con cartas al director y la opinión de un personaje famoso $^{5}$ sobre un tema general $(37,38 \%)$..

3) En Deportes con el 80,36 \% se desglosa en las siguientes actividades: El Fútbol es la sección con mayor número de páginas $(29,16 \%)$ recoge amplia información sobre $3^{\circ}$ División; Regional preferente; Fútbol sala y $1^{\circ}$ Regional. Polideportivo muestra la actualidad deportiva de Pelota, petanca y balonmano, baloncesto, gimnasia, tenis, herri kirolak (12,50 \%). Ciclismo, Artes marciales, Voleibol, Atletismo y Motor son especialidades deportivas que varían según la temporada (4,16\%). En Motor ofrece información sobre competiciones y campeonatos que van a tener lugar en fechas próximas $(5,16 \%)$. Montañismo presenta las escaladas importantes, así como las actividades y deportes relacionados con la montaña $(5,16 \%)$. También presta atención a los acontecimientos deportivos que se celebran en cada temporada entre ellos destacan Balonmano, Voleibol, Atletismo, Motor, Rugby, Béisbol y Remo (25,06 \%).

5 Cesar Savedra. Días de mucho vipéreas de nada. La Grada Margen Izquierda. núm.22. Junio 1999. 
4) En Racing Press la mitad de su superficie está destinada a texto con contenido informativo (46,56 \%), mientras que la publicidad supone el 36,32 \% y la fotografía con el $15,12 \%$. Los distintos contenidos los agrupa en las siguientes secciones:

1) Las Noticias con los teléfonos de interés, los lugares donde es posible adquirir la publicación y la programación de motor en las distintas emisoras de radio $(4,26 \%)$.

2) En motor incluye: La Entrevista a personajes relevantes relacionados con el mundo del motor (6,30 \%). Divulgación de actividades vinculadas con el motor en sus diversos aspectos es una sección con amplia presencia (17\%). En Campeonatos incluye las clasificaciones de las competiciones nacionales de rallys de asalto, tierra, autocross y montaña $(23,65 \%)$. En el Motor (10,64 \%) nos acerca a las ultimas novedades del mercado, junto con sus ventajas e inconvenientes. En conjunto alcanza casi el $90 \%$ del total ed los contenidos.

4) La actualidad en el mundo del motor y los precios de los vehículos y motos nuevas $(6,30 \%)$.

4) Wellcome Euskadi tiene más de la mitad de su superficie destinada a contenidos informativos 58,74 \% y sólo el 15,46 \% de publicidad. Carece de secciones determinadas aunque se ocupa de la información sobre el País Vasco en general, las visitas turísticas a las tres capitales, los museos, la gastronomía y todas aquellas informaciones que resulten interesantes para los turistas.

\section{Cuadro n. 9}

Los contenidos en los gratuitos Especializados. Año 2000

Montañas Bizkai-Lan Grada Racing Wellcome

$\begin{array}{lrrrrr}\text { Actualidad } & 13,28 & 15,92 & 0,00 & 6,30 & 0,00 \\ \text { Viajes } & 6,28 & 0,00 & 0,00 & 0,00 & 93,55 \\ \text { Deportes } & 39,04 & 0,00 & 80,36 & 0,00 & 0,00 \\ \text { Suplemento } & 26,45 & 37,38 & 0,00 & 0,00 & 0,00 \\ \text { Guia } & 7,14 & 3,40 & 4,16 & 4,26 & 6,45 \\ \text { Infraestructuras } & 0,00 & 14,90 & 0,00 & 0,00 & 0,00 \\ \text { Trabajo } & 0,00 & 19,87 & 0,00 & 0,00 & 0,00 \\ \text { M. Ambiente } & 0,00 & 9,43 & 0,00 & 0,00 & 0,00 \\ \text { Opinión } & 0,00 & 0,00 & 5,16 & 0,00 & 0,00 \\ \text { Motor } & 0,00 & 0,00 & 5,16 & 89,44 & 0,00 \\ \text { Otros } & 7,81 & 0,00 & 5,16 & 0,00 & 0,00\end{array}$




\section{8) La publicidad en los gratuitos especializados}

La financiación es uno de los principales problemas con los que se encuentran los editores, y por ello ofrecen unos precios muy competitivos con el fin de captar los pequeños comerciantes. El precio orientativo de un módulo oscila entre las 2.000 pesetas en La Grada y las 3.500 en Bizkai-Lan. Sus clientes se centran básicamente en:

1) Establecimientos comerciales principalmente relacionadas con la especialización de sus contenidos.

2) Firmas comerciales de ámbito nacional.

3) Publirreportajes.

\section{Cuadro n. 10}

Tarifas Publicitarias. Año 2.000

Bizkai-Lan La Grada Racing-Press Wellcome E.

$\begin{array}{lrrrr}1 \text { Módulo } & 3.500 & 2.000 & 3.500 & 3.000 \\ \text { Faldón portada } & 105.000 & 20.000 & 35.000 & 62.000 \\ \text { Faldón contrap. } & 105.000 & 20.000 & 15.000 & 62.000 \\ \text { Página } & 126.000 & 100.000 & 150.000 & 95.000\end{array}$

En cuanto a la publicidad destacan los siguientes sectores:

1) En Montañas y Tiempo Libre se encuentra una publicidad vinculada con los contenidos. Mayoritariamente, está dirigida a un público con aficiones por los deportes al aire libre y la montaña principalmente. De modo, que lo centra en servicios relacionados con restaurantes $(33,96 \%)$, viajes $(22,50 \%)$ y las actividades deportivas $(15,54 \%)$. No obstante, la publicidad que más espacio ocupa son los deportes con el 41,70\%, seguida de los restaurantes con el $30 \%$ ). Es decir su publicidad esta relacionada con los contenidos que aborda en sus páginas.

2) En Bizkai-Lan la publicidad significa casi la cuarta parte de la superficie total, que centra básicamente en materias relacionadas con las actividades que aborda, por lo tanto es especifica como lo son sus contenidos que inciden en los siguientes sectores: Institucional que alcanza el 13,51\% del total de la publicidad, y además ocupa el 26,39 \% de la superficie total del gratuito. La industria que constituye el $62,18 \%$ del total: Obras y servicios $(24,37 \%)$, los transportes con el $13,50 \%$, además de aislantes $(5,40 \%)$; alquiler de maquinaria $(5,40 \%)$ y calefacción $(5,40 \%)$ entre otros.

3) En la Grada la publicidad se centra principalmente en los establecimientos de su zona de cobertura. También son frecuentes las inserciones publicitarias 
de quioscos de prensa y esto el lógico si tenemos en cuenta que se distribuye en estos lugares de manera gratuita. Los contenidos publicitarios inciden en: los establecimientos relacionados con la hostelería $(32,03 \%)$; los deportes $(13,23 \%)$ y el automóvil (12,86\%)

4) Racing Press concentra más de la mitad de la publicidad en el mundo del automóvil $(65 \%)$ como puede ser la Compra venta de vehículos; Los Talleres de reparación, chapa y electricidad, y Accesorios para vehículos. Situación que se repite con el espacio que contratan $(69,73 \%)$.

5) Wellcome es el gratuito con mayor publicidad institucional $(45,55 \%)$, seguida del automóvil $(18,18 \%)$ que se centra principalmente en el alquiler de vehículos $(18,18 \%)$; Telefonía, que ofrece información sobre llamadas provinciales y móviles de Euskaltel y en Moda y belleza recomiendan los centros de belleza y tiendas de moda de mayor prestigio $(9,00 \%)$.

\section{Cuadro n. 11}

Número de anuncios por temas. Año 2000

Montañas Bizkai-Lan Grada Racing Wellcome

$\begin{array}{lrrrrr}\text { Enseñanza } & 0,00 & 0,00 & 8,16 & 1,00 & 0,00 \\ \text { Medicina } & 0,00 & 0,00 & 4,91 & 0,00 & 0,00 \\ \text { Muebles } & 0,00 & 0,00 & 3,43 & 0,00 & 0,00 \\ \text { Reformas } & 0,00 & 5,40 & 7,46 & 0,00 & 0,00 \\ \text { Automóvil } & 0,00 & 0,00 & 12,86 & 65,00 & 18,18 \\ \text { Deportes } & 15,54 & 0,00 & 13,25 & 7,50 & 9,09 \\ \text { Inmobiliaria } & 0,00 & 0,00 & 0,00 & 0,00 & 0,00 \\ \text { Restaurantes } & 33,96 & 5,40 & 32,03 & 7,50 & 0,00 \\ \text { Moda } & 0,00 & 0,00 & 0,00 & 0,00 & 9,09 \\ \text { Informática } & 3,00 & 0,00 & 2,28 & 0,00 & 0,00 \\ \text { Varios } & 25,50 & 13,51 & 12,74 & 19,00 & 9,09 \\ \text { Viajes } & 22,50 & 0,00 & 0,00 & 0,00 & 0,00 \\ \text { Fotografía } & 0,00 & 0,00 & 2,88 & 0,00 & 0,00 \\ \text { Industria } & 0,00 & 62,18 & 0,00 & 0,00 & 0,00 \\ \text { Institucional } & 0,00 & 13,51 & 0,00 & 0,00 & 45,55 \\ \text { Telefonía } & 0,00 & 0,00 & 0,00 & 0,00 & 9,00\end{array}$


Cuadro n. 12

Superficie publicitaria por temas. Año 2000

Montañas Bizkai-Lan Grada Racing Wellcome

$\begin{array}{lrrrrr}\text { Enseñanza } & 0,00 & 0,00 & 6,64 & 1,50 & 0,00 \\ \text { Medicina } & 5,20 & 0,00 & 8,52 & 0,00 & 0,00 \\ \text { Muebles } & 0,00 & 0,00 & 5,24 & 0,00 & 0,00 \\ \text { Reformas } & 0,00 & 5,94 & 5,52 & 4,47 & 0,00 \\ \text { Automóvil } & 0,00 & 0,00 & 9,09 & 69,73 & 38,03 \\ \text { Deportes } & 41,70 & 0,00 & 12,70 & 7,48 & 9,87 \\ \text { Inmobiliaria } & 0,00 & 0,00 & 3,70 & 0,00 & 0,00 \\ \text { Restaurantes } & 31,60 & 5,94 & 27,34 & 4,07 & 0,00 \\ \text { Moda } & 0,00 & 0,00 & 0,00 & 0,00 & 14,26 \\ \text { Informática } & 0,00 & 0,00 & 2,52 & 0,00 & 0,00 \\ \text { Varios } & 11,11 & 7,18 & 8,13 & 12,75 & 9,78 \\ \text { Viajes } & 10,39 & 0,00 & 0,00 & 0,00 & 0,00 \\ \text { Fotografía } & 0,00 & 0,00 & 10,60 & 0,00 & 0,00 \\ \text { Industria } & 0,00 & 54,55 & 0,00 & 0,00 & 0,00 \\ \text { Institucional } & 0,00 & 26,39 & 0,00 & 0,00 & 13,58 \\ \text { Telefonía } & 0,00 & 0,00 & 0,00 & 0,00 & 14,48\end{array}$

\section{Bibliografia}

- BOGART, Leo. La prensa y su público. EUNSA. Pamplona, 1985.

- COCA, Cesar y PEÑALVA, José Luis. Modelos de los medios de comunicación social. U.P.V. Bilbao, 1998.

- DIEZHANDINO NIETO, M. Pilar, La especialización en los medios impresos, en Bezunartea y otros. La prensa ante el cambio de siglo. Deusto. Bilbao, 1988.

- DIEZHANDINO NIETO, Pilar. Periodismo de servicio: Evolución y Perspectivas. Bilbao 1994

- FERRER RODRIGUEZ, Eulalio. La historia de los anuncios por palabras. Maeva Ediciones. Madrid, 1989.

- MOELING, M. Just What is service Journalism. Service Journalism Dialogue. 1988.

- NIETO, Alfonso. La prensa gratuita. EUNSA. Pamplona, 1984.

- SANTOS DIEZ, M. Teresa. Prensa gratuita vasca: Información o Publicidad. R. Sintonía, Bilbao, 1996.

- SCOTT, Byron. Conference addresses urgent Needs. Service Journalism Program, School of Journalism, University of Missouri, Columbia, 1988. 


\section{ANEXO}

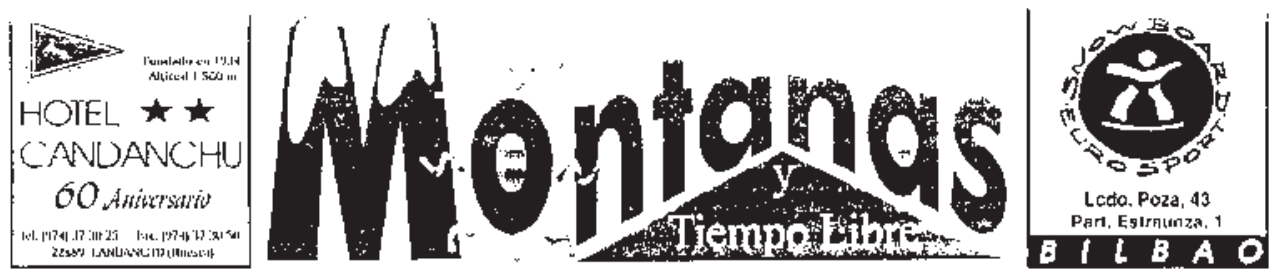

PERIODICO GRATUITO

ANO 1. N: 1. DICIEMBRE 1994 VIAJES - DEPORTE - NATURALEZA - TURISMO - AVENTURA - OCIO
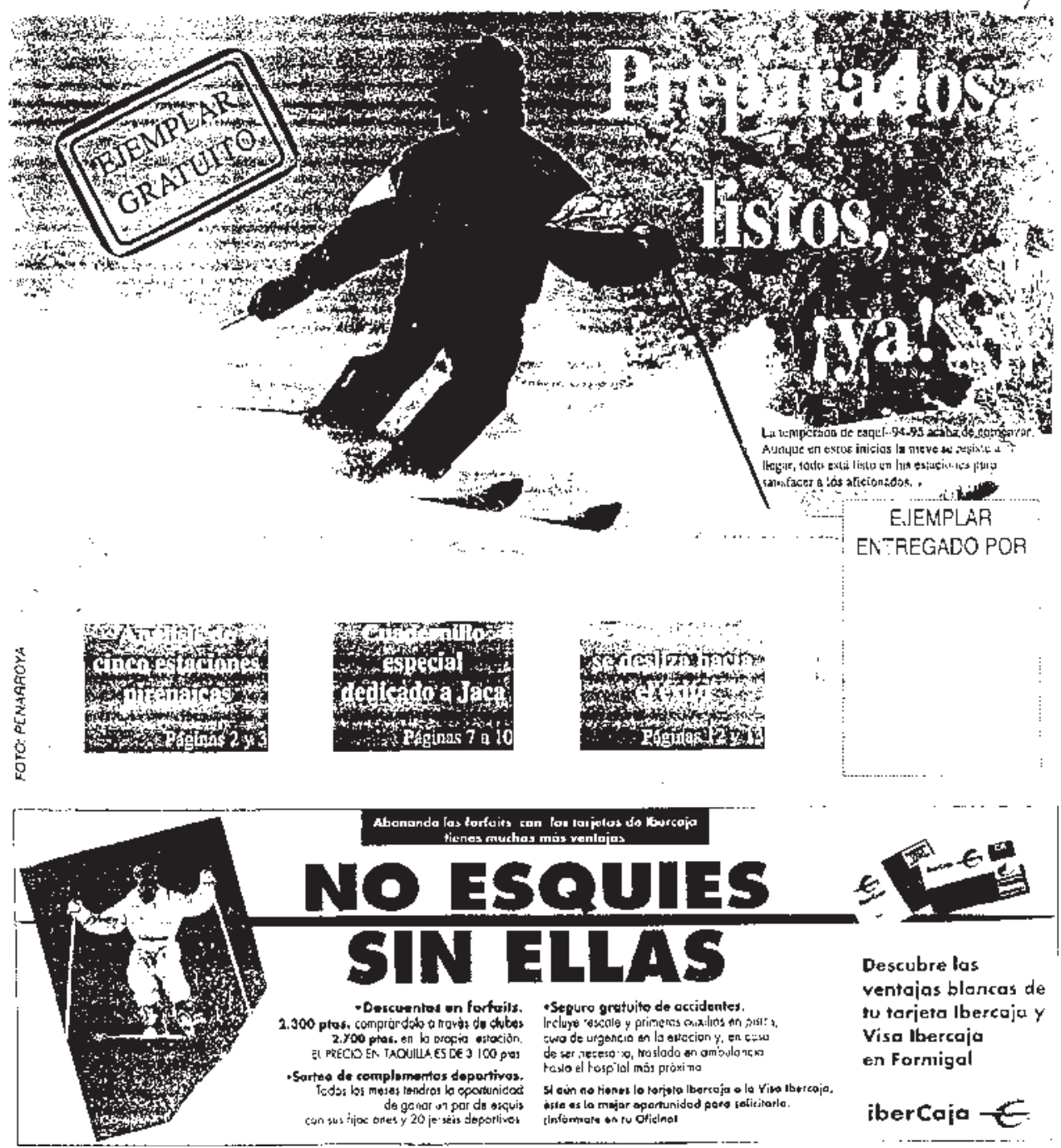

Descubre los

ventajas blancas de tu tariera lbercaja y Visa lbercajo en Formigal iberCaja $t$ 

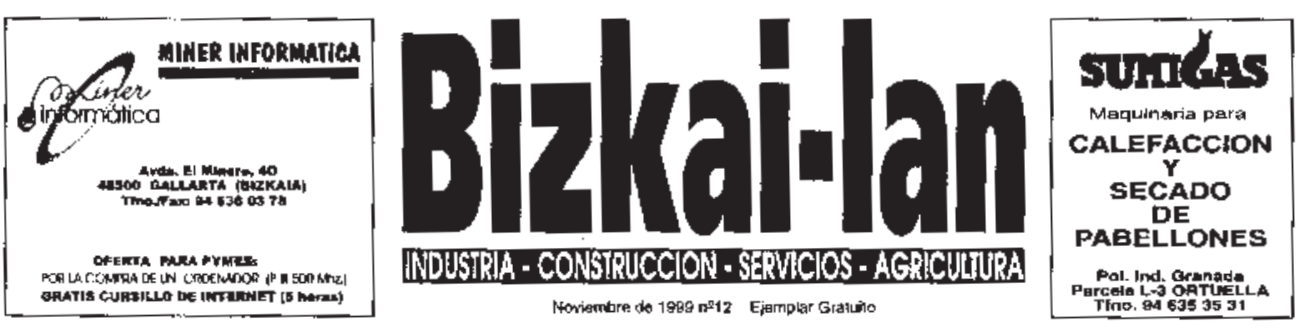

\section{La muestra Prest '99 repite el éxito cosechado en 1998}

\section{Entidades, empresas y centros educativos se juntaron para debatir sobre la formacion y el empleo del año 2000}

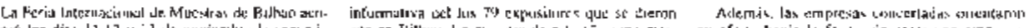

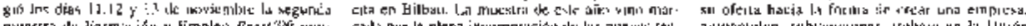

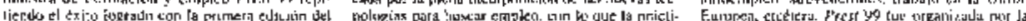

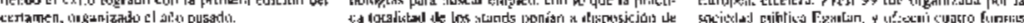

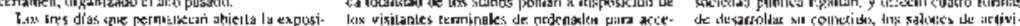

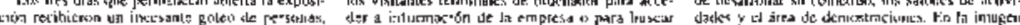

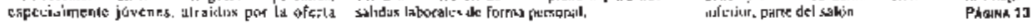
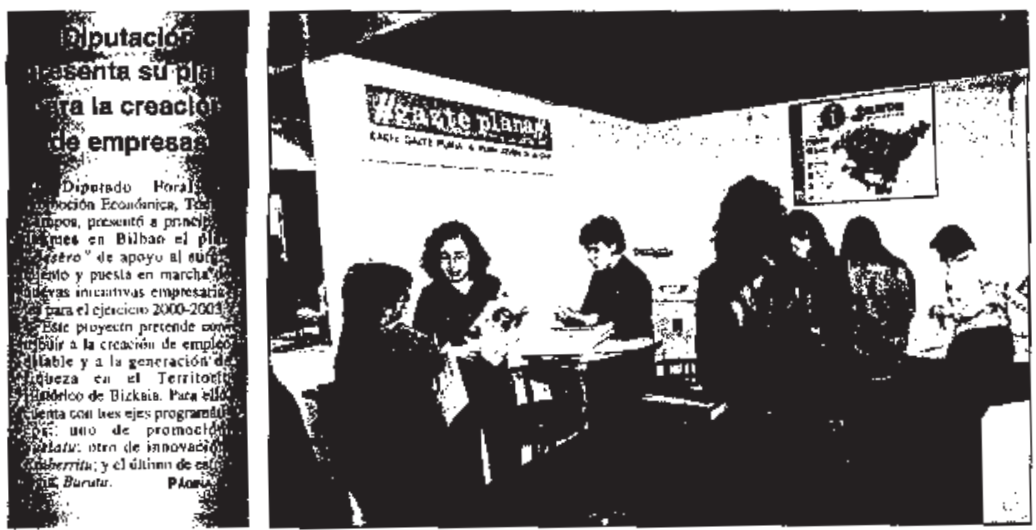

SPAl apruge jt pere regros Pramedeb

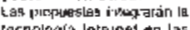
Gapipsas. Papina?

Tres uftos quer nas esmbiarart et menotion

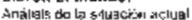

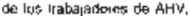

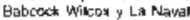

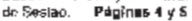

Er Pstriso de guluso solucicard an brawe one

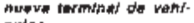
Fulas.

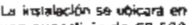
una supermicie da 62.

Acutation mobre ol truth

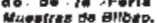

La Fastre to intralart an

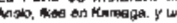

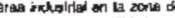

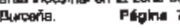

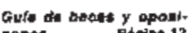
Eonel- Pogine 12

Eurkath redula wu lese

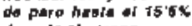

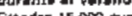

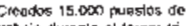
resto

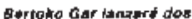
Adewis prodtucios.

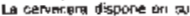
plenta tó IJte tnsla uranlt-

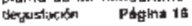

Ampilsas bopeficios on A EVE.
Ohpellos. Pdplne 19

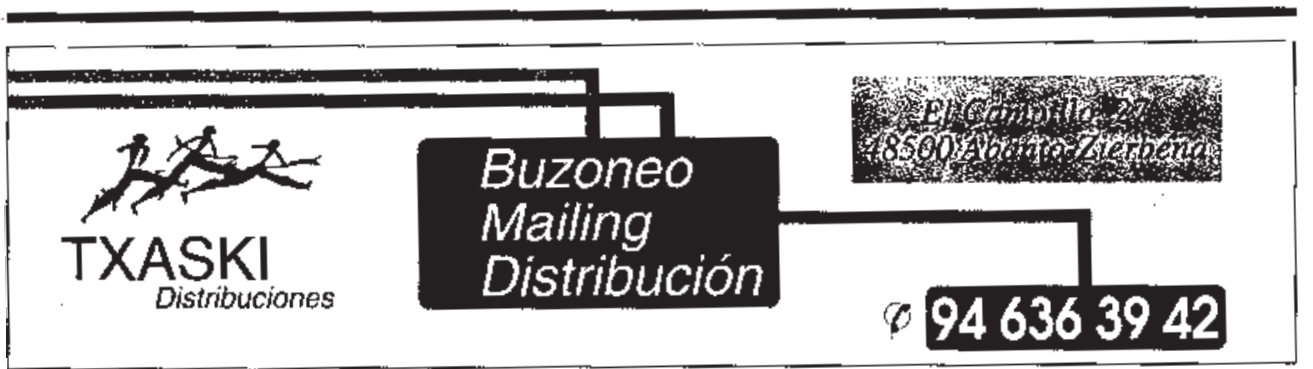




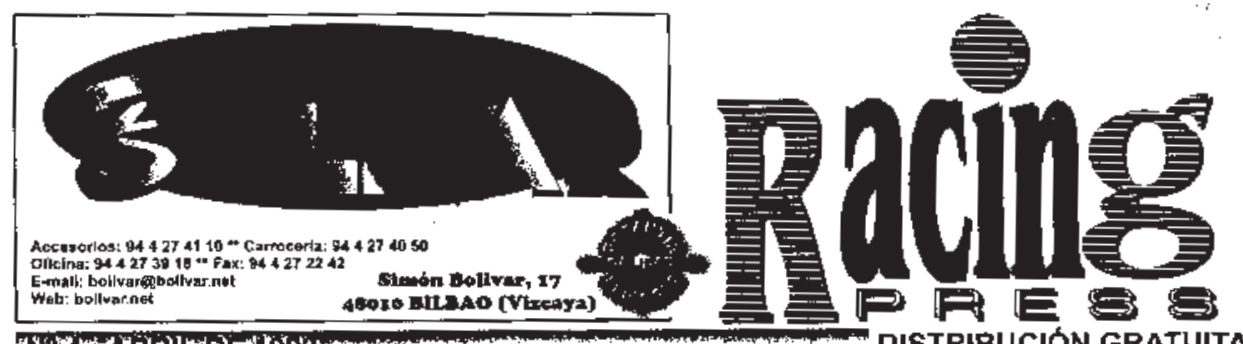

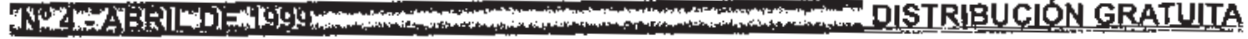
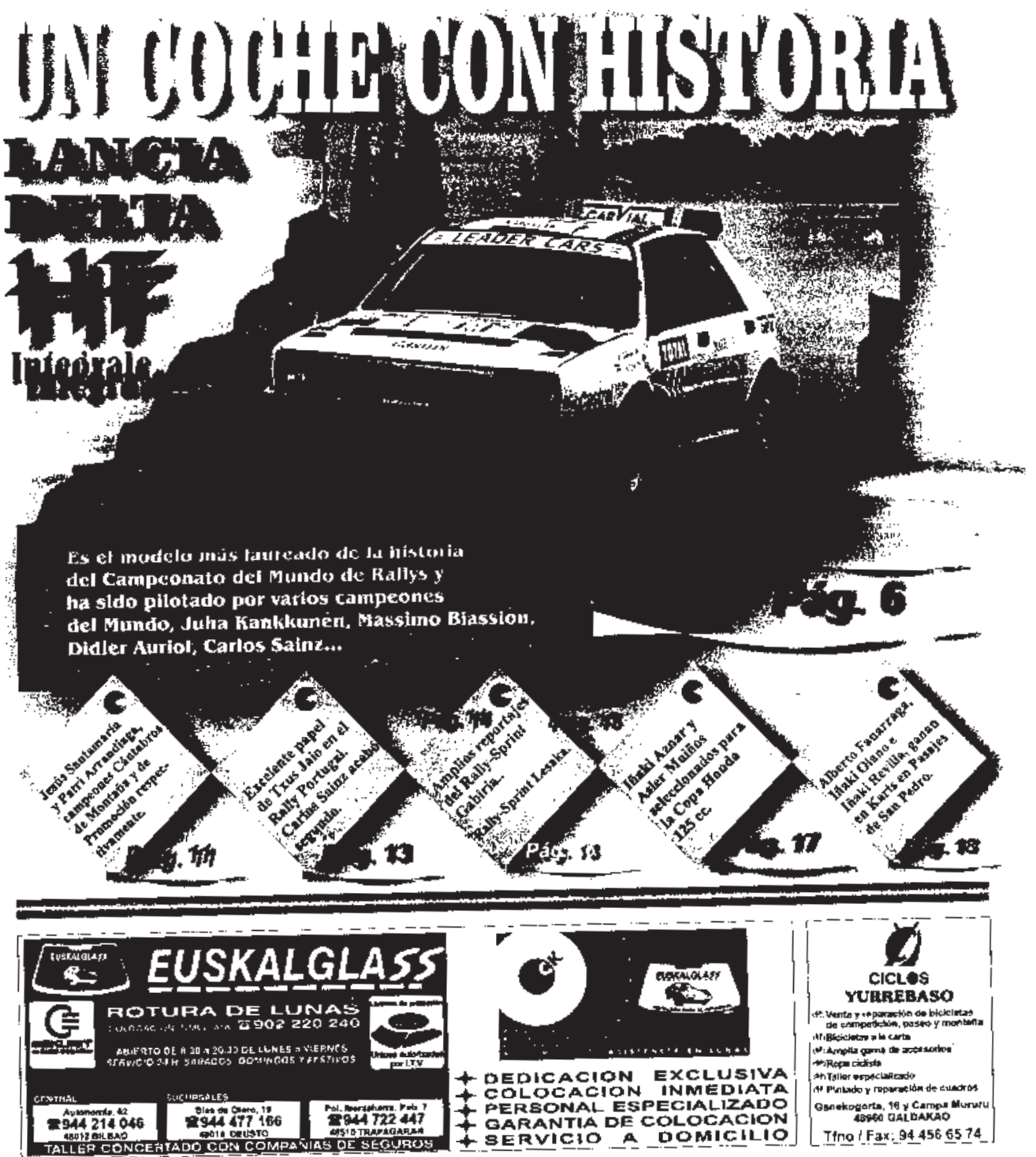

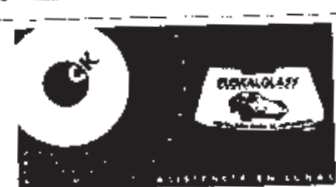

- DEDHCACION EXCLUSIVA * Colocacion inNeBLATa * personal especializado + garantia de colocacion + gervejo a domichlo

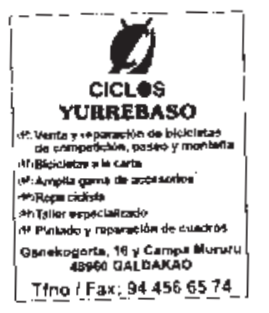




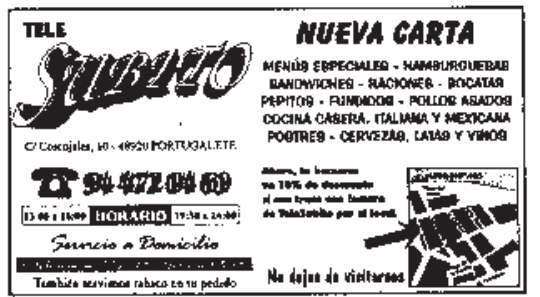

ANO III - N" 21. HAYO DA

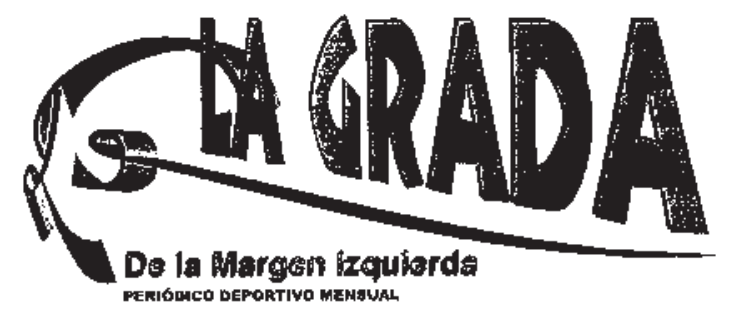

In: DISTFIFUCIOW CRATUITA
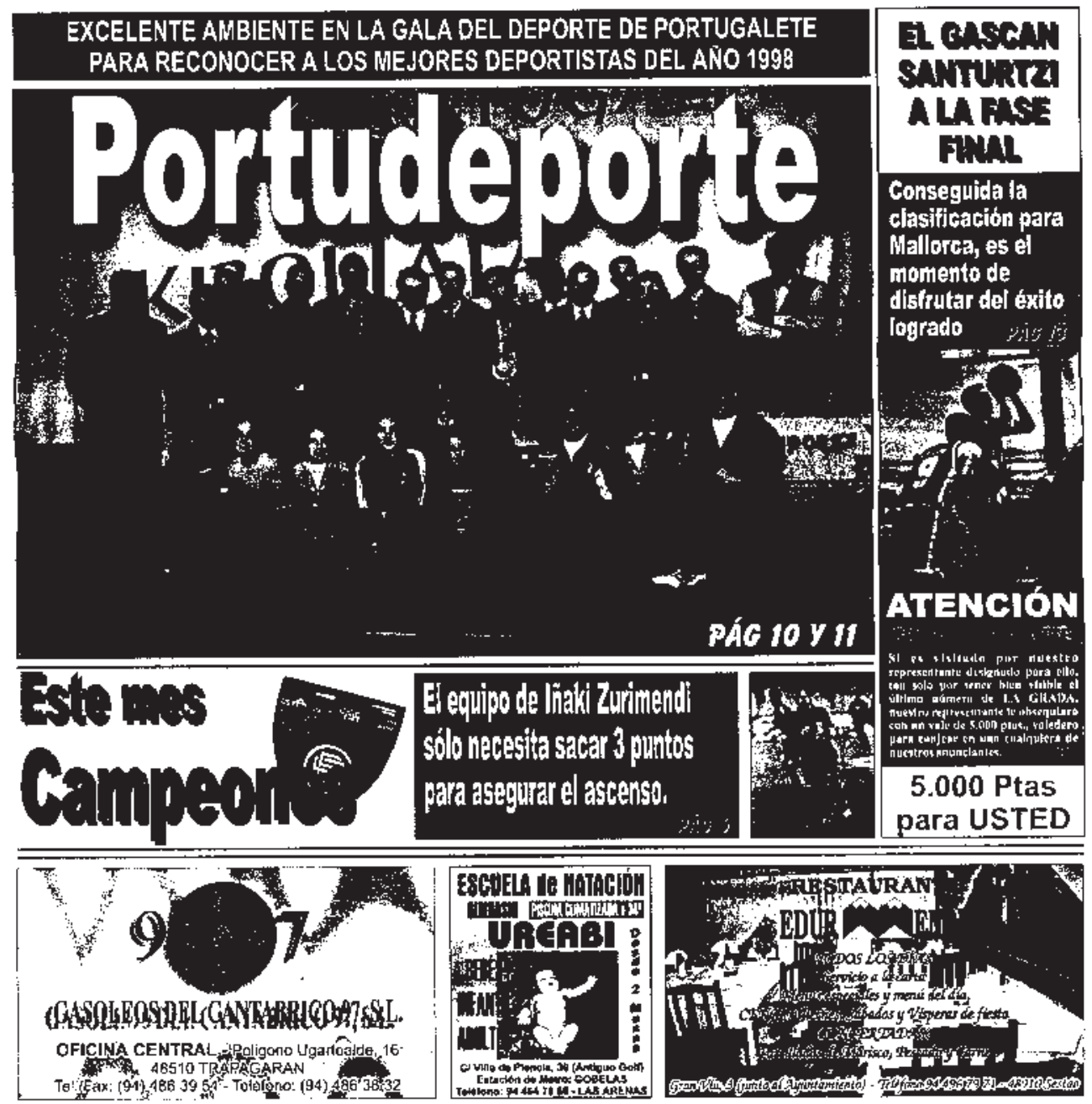

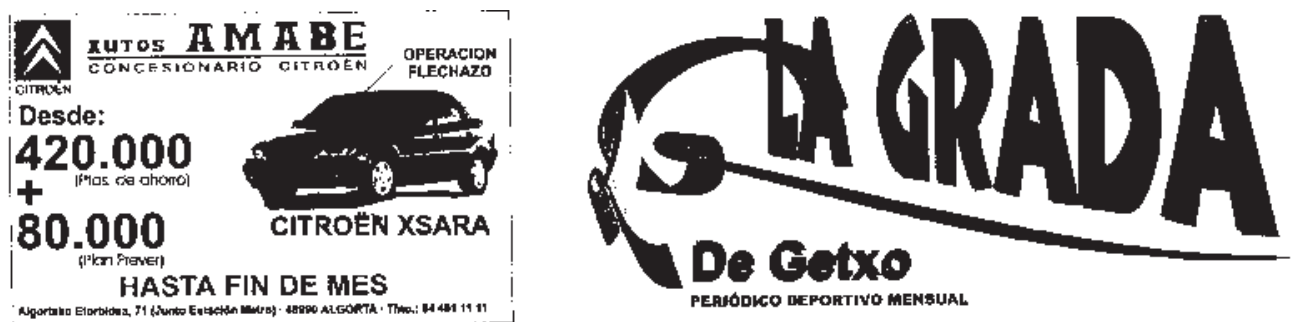

ANO H - N 12 - MARZOC-ABRL 99

CON MANU VITORIA COMO NUESTRO MAS AVALADO REPRESENTANTE
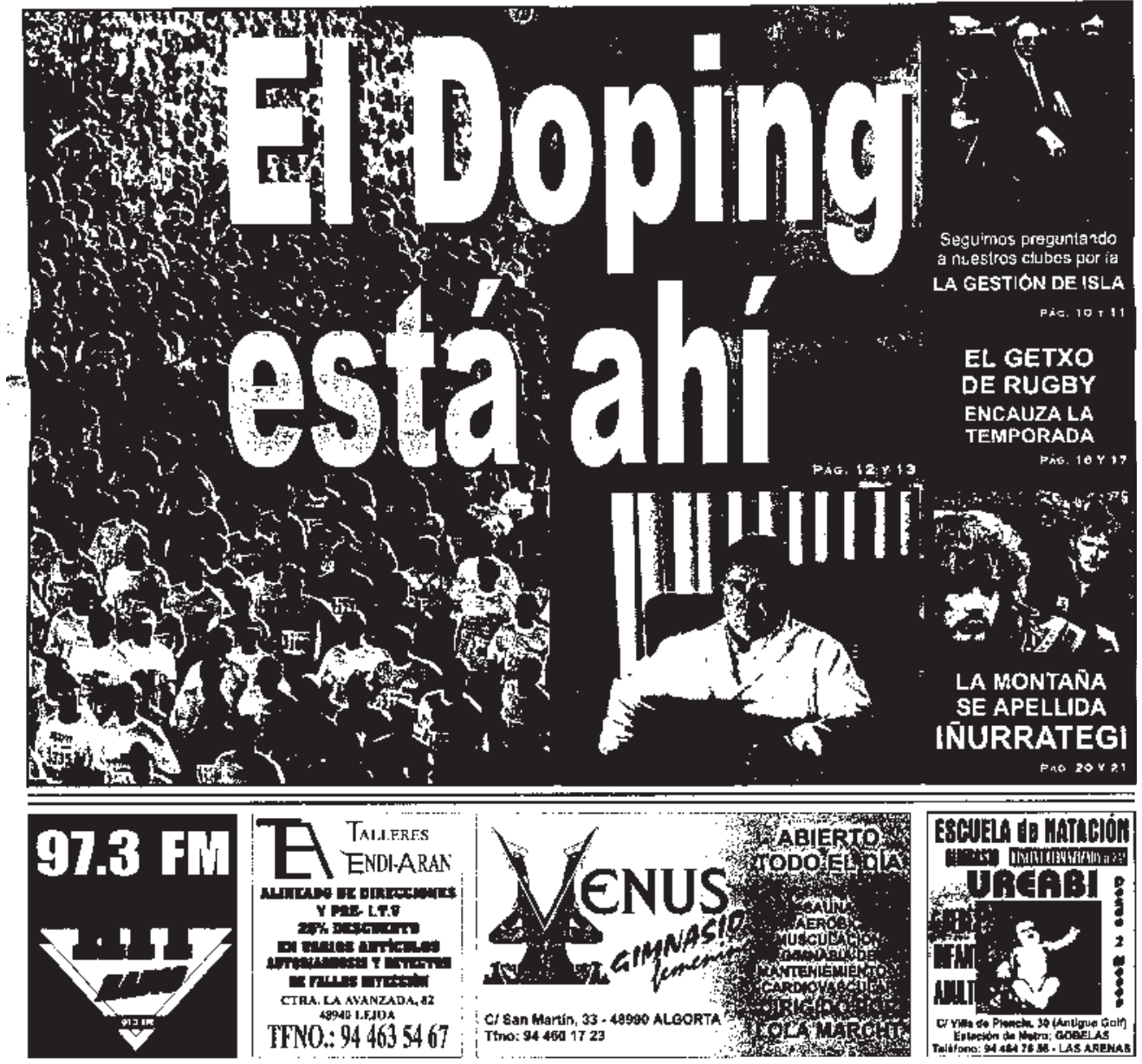


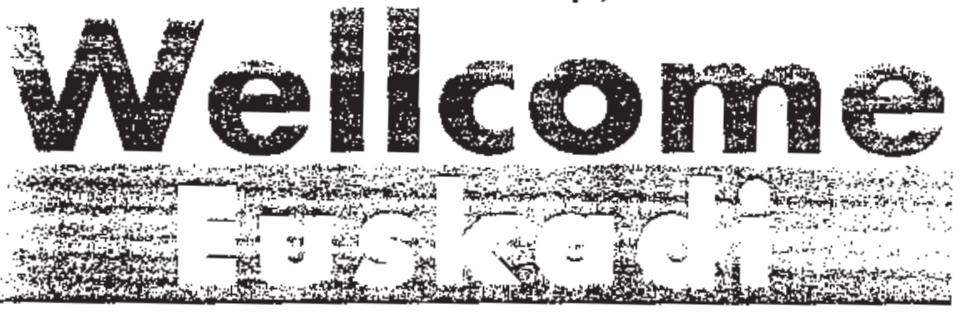

El Periódico de Información Turística de Euskadi The Basque Country Touristic Information Newspaper
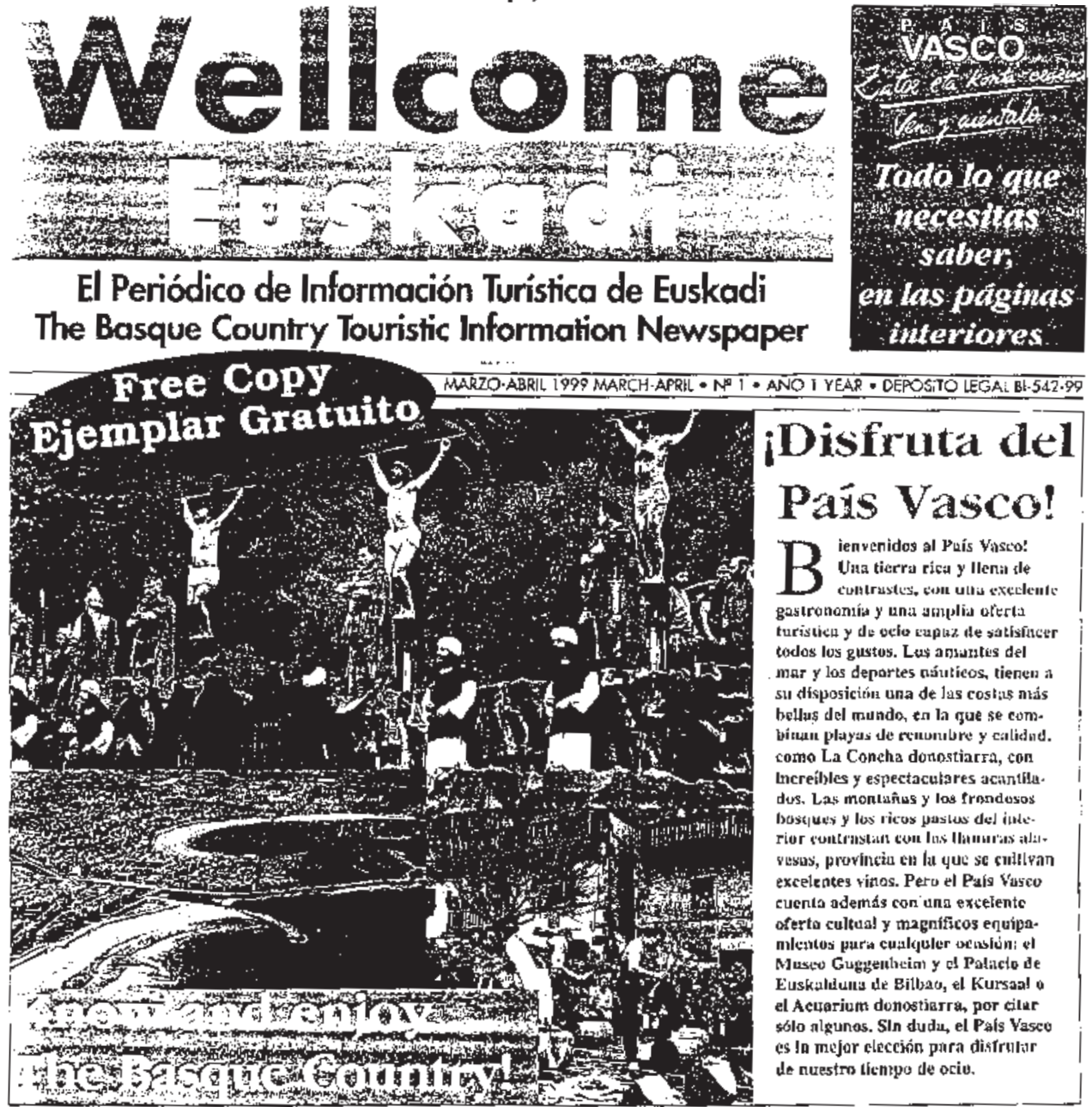

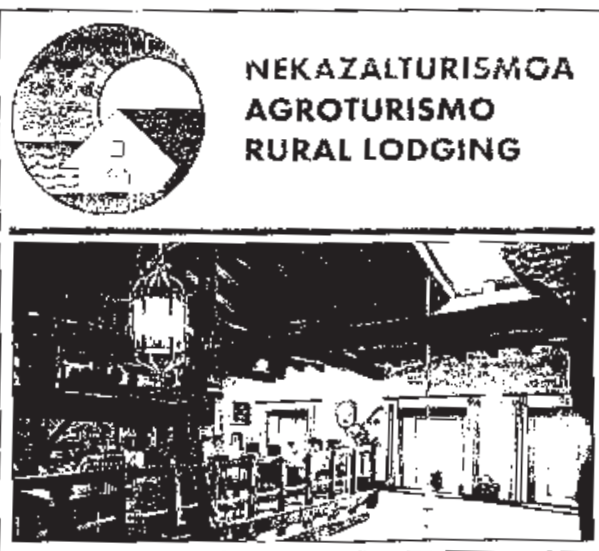

"Numerous possibilities are opened up with kind of tourism" Sremd a tew days sualiang up the mut unat sultroundingy. Take an itctiys pust in the

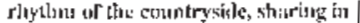

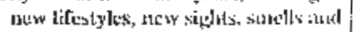

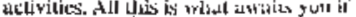
pou dforde to toke adsantage of Agroturismion ot Rural Accommodationts. Euskadi ullers: a wide

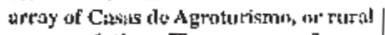
apcosimodutions. They are purt of in hitu Hork based on louging in farmhouses and sratl hovels; i phenornent which is beoming more popular and better otronnlatil all the time. In thest aceromandaJons, one cari retax'ant enjoy the untchors in cxecptionul surmuntings.

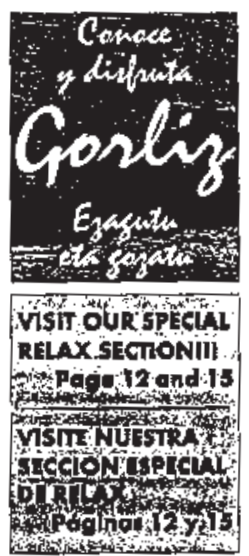

